\title{
Current treatment options for psoriatic arthritis: spotlight on abatacept
}

This article was published in the following Dove Press journal:

Therapeutics and Clinical Risk Management

\author{
Francesco Ursini ${ }^{1,2}$ \\ Emilio Russo' \\ Roberto De Giorgio 3 \\ Giovambattista De Sarro' \\ Salvatore D'Angelo ${ }^{4,5}$ \\ 'Department of Health Sciences, \\ University of Catanzaro "Magna \\ Graecia", Catanzaro, Italy; \\ ${ }^{2}$ Associazione Calabrese per la \\ Ricerca in Reumatologia, Catanzaro, \\ Italy; ${ }^{3}$ Department of Medical \\ Sciences, University of Ferrara, \\ Ferrara, Italy; ${ }^{4}$ Rheumatology \\ Department of Lucania, Rheumatology \\ Institute of Lucania (IReL), Potenza \\ Italy; ${ }^{5}$ Basilicata Ricerca Biomedica \\ (BRB), Potenza, Italy
}

\begin{abstract}
Psoriatic arthritis (PsA) is a chronic inflammatory disease of joints, tendon sheaths, and entheses affecting patients with established skin psoriasis, or, less frequently, patients without a personal history of psoriasis with a positive familial history. Many treatment options are now available to deal with the different aspects of the disease, including traditional and biological disease-modifying antirheumatic drugs and the recently released targeted synthetic disease-modifying antirheumatic drugs. However, $\sim 40 \%$ of patients still fail to achieve a meaningful clinical response to first-line biologic therapy advocating the development of novel medications. It is now well accepted that T-cells participate in the immunopathogenesis of several autoimmune diseases. For this reason, the potential intervention on T-cells represented an attractive therapeutic target for a long time, becoming a clinical reality with the development of abatacept. Abatacept is a biologic agent selectively targeting the T-cell costimulatory signal delivered through the CD80/86-CD28 pathway and was approved in December 2005 by the US Food and Drug Administration and in May 2007 by European Medicines Agency for the treatment of patients with rheumatoid arthritis in combination with methotrexate. Based on the relevant role of T-cells in PsA pathogenesis and following the positive results obtained in a phase III clinical trial, abatacept recently received approval for treatment of patients with PsA. In this review, we will focus on the current knowledge about the emerging role of abatacept in treatment of PsA.
\end{abstract}

Keywords: abatacept, CTLA4-Ig, T-cell, psoriatic arthritis, efficacy, safety

\section{Introduction}

Psoriatic arthritis (PsA) is a chronic inflammatory disease of joints, tendon sheaths, and entheses affecting patients with established skin psoriasis (Pso), or - less frequently - patients without a personal history of Pso exhibiting a positive familial history. ${ }^{1}$ Musculoskeletal presentation may embrace a variety of clinical pictures including poly- or oligo-arthritis, destructive arthritis of distal interphalangeal joints, dactylitis, enthesitis, or predominantly axial disease. ${ }^{1}$ Moreover, PsA patients are burdened by several comorbidities such as obesity, type 2 diabetes/insulin resistance, metabolic syndrome, hypertension, and hyperlipidemia, ${ }^{2-4}$ which, by synergizing with the systemic inflammatory process, lead to an overall increase in prevalence and incidence of cardiovascular diseases. ${ }^{5}$ The heterogeneity of PsA phenotype fostered the development of the novel concept of "psoriatic disease" 6 to better emphasize the pleiotropic nature of this condition.

Many treatment options are now available to deal with the different aspects of the disease, including conventional synthetic and biologic disease-modifying antirheumatic drugs (DMARDs) and the recently released targeted synthetic DMARDs (tsDMARDs). However, $\sim 40 \%$ of patients still fail to achieve a meaningful clinical
Correspondence: Francesco Ursini Department of Health Sciences, University of Catanzaro "Magna Graecia", Viale Europa, I - 88I00 Catanzaro, Italy Tel +393928759870

Email francesco.ursini@yahoo.it 
response to first-line biologic therapy, ${ }^{7,8}$ advocating the development of novel medications.

It is now well accepted that T-cells participate in the immunopathogenesis of several autoimmune diseases. ${ }^{9}$ For this reason, potential intervention on T-cells represented an attractive therapeutic target for a long time, which became a clinical reality only following the development of abatacept. Abatacept is a biologic agent selectively targeting the T-cell costimulatory signal delivered through the CD80/86-CD28 interaction and was approved in December 2005 by the Food and Drug Administration (FDA) and in May 2007 by European Medicines Agency (EMA) for the treatment of patients with rheumatoid arthritis (RA) in combination with methotrexate (MTX).

The broad mechanism of action of this molecule raised the hypothesis that abatacept may hijack the pathophysiological mechanisms underlying many other immune-mediated diseases sharing the key role of T-cells. Encouraging data are now emerging regarding the potential usefulness of abatacept in some of them (type 1 diabetes, ${ }^{10}$ giant cell arteritis, ${ }^{11}$ dermatomyositis, ${ }^{12}$ and Sjögren's syndrome ${ }^{13}$ ), while in other diseases (systemic lupus erythematosus, ${ }^{14}$ Takayasu's arteritis, ${ }^{15}$ ulcerative colitis/Crohn's disease, ${ }^{16}$ and multiple sclerosis ${ }^{17}$ ) preliminary studies found no significant benefits, underlying the complex, differential interaction of profoundly diverse T-cells lineages, and between T-cells and other immune effector cells.

In this review, we will focus on the current knowledge on the emerging role of abatacept in treatment of PsA.

\section{Current treatment options for PsA}

In order to assist rheumatologists in everyday clinical practice, different international and national recommendations for the management of PsA patients have been developed to date, such as the Group for Research and Assessment of Psoriasis and Psoriatic Arthritis (GRAPPA) $)^{18}$ and the European League Against Rheumatism (EULAR) ${ }^{19}$ recommendations.

Latest EULAR recommendations for pharmacological treatment of PsA comprise 5 overarching principles and 10 recommendations concerning nonsteroidal anti-inflammatory drugs (NSAIDs), conventional synthetic DMARDs (csDMARDs), tsDMARDs, and biological DMARDs (bDMARDs) including originator or biosimilar TNF inhibitors, anti-IL-12/23, and anti-IL-17 agents. GRAPPA recommendations take in account both dermatological and musculoskeletal involvement and are organized in 6 domains (peripheral arthritis, axial disease, enthesitis, dactylitis, and skin and nail involvement) based on the predominant manifestation.
According to EULAR, MTX is the first csDMARD to be used in patients suffering from peripheral arthritis. However, sulfasalazine, leflunomide, and cyclosporine are considered only when MTX is contraindicated or has already failed. On the other hand, GRAPPA recommends MTX, sulfasalazine, or leflunomide as the first option without a definite preference.

In patients with peripheral arthritis and an inadequate response to at least 1 csDMARD, a bDMARD - usually a TNF inhibitor - should be initiated according to the EULAR recommendations. When TNF inhibitors are not appropriate, bDMARDs targeting IL-12/23 or IL-17 axis may be considered. In patients in whom bDMARDs are not appropriate, tsDMARDs - such as the phosphodiesterase 4 (PDE-4) inhibitor apremilast - may be considered. On the contrary, GRAPPA experts place TNF inhibitors, other bDMARDs, and PDE-4 inhibitors at the same level as a potential first choice in PsA patients with an inadequate response to at least 1 csDMARD.

Both GRAPPA and EULAR suggest an early use of bDMARD in patients with active enthesitis and/or dactylitis and insufficient response to NSAIDs or local glucocorticoid injections. A similar approach is reserved for patients with predominantly axial disease and insufficient response to NSAIDs.

\section{Introduction to abatacept Physiology of T-cell costimulation}

Upon generation, T-cells circulate in an anergic state waiting to become "activated" and subsequently perform their role of master players of the adaptive arm of the immune system. Complete T-cell activation requires 2 distinct receptor interactions with antigen-presenting cells (APCs) to be accomplished (Figure 1A). ${ }^{20}$ The first is the encounter between the major histocompatibility complex (MHC), present on the surface of APCs and exposing an antigenic peptide, and the T-cell receptor (TCR) found on the membrane of all T-cells. The second - the so-called costimulatory signal - is mainly, but not only, mediated by the interaction between the CD80 (B7-1)/CD86 (B7-2) molecules on the membrane of APCs with the CD28 receptor expressed by T-cells. ${ }^{20,21}$ Other molecules, such as CD2, can deliver alternative costimulatory signals. ${ }^{22} \mathrm{CD} 28$ is expressed constitutively on T-cells, and its engagement leads to full activation; ${ }^{23}$ however, important differences exist between T-cell compartments, with the memory subset being less dependent on costimulation than the naïve counterpart. ${ }^{24}$ To counteract an excessive activation of T-cells, an autoregulatory mechanism starts $\sim 48$ hours after activation. CTLA-4 is indeed transiently expressed 

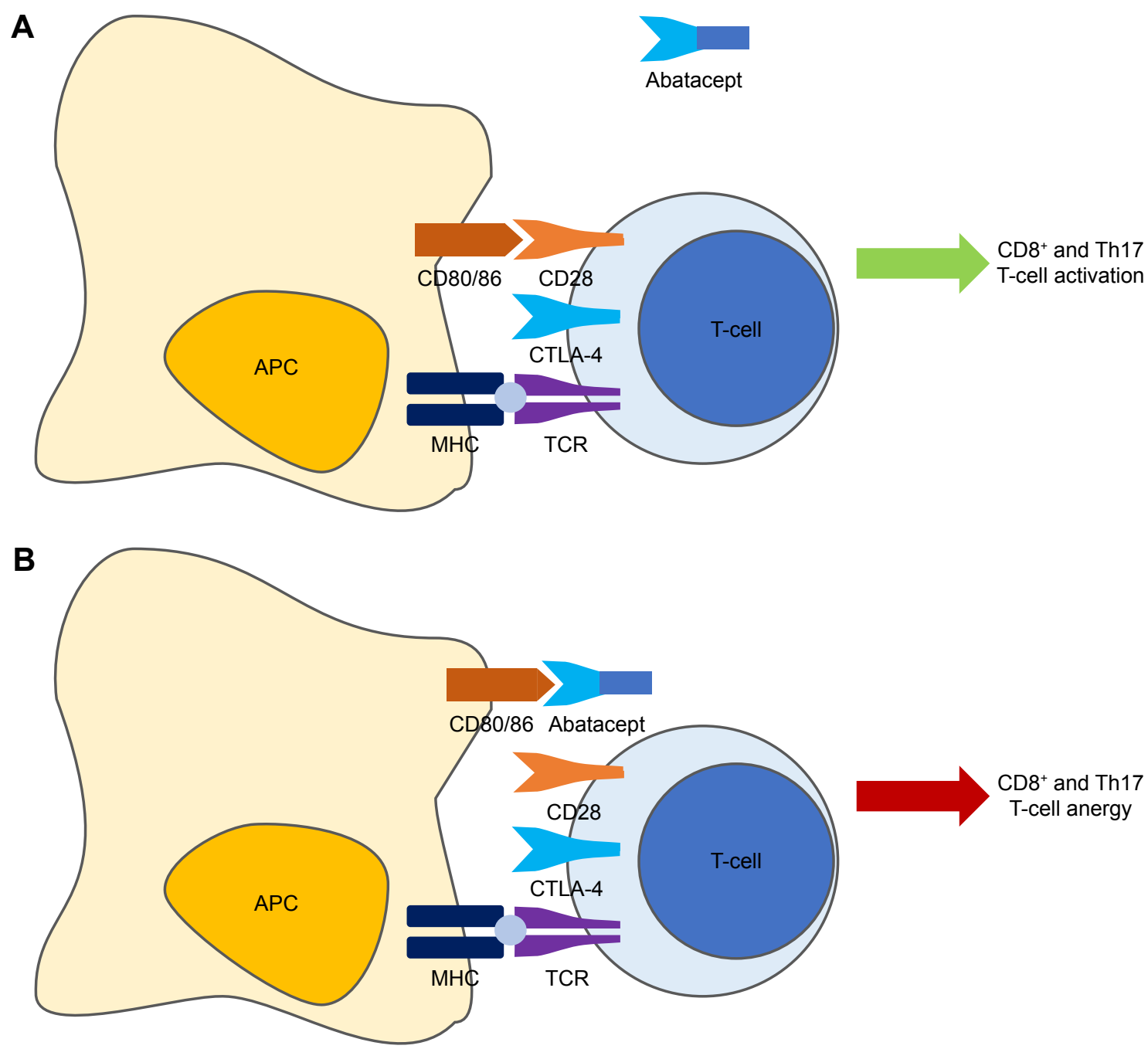

Figure I Mechanism of action of abatacept.

Notes: Complete T-cell activation requires 2 distinct receptor interactions with APCs to be accomplished. The first is the encounter between the MHC and the TCR found on the membrane of all T-cells. The second - the so-called costimulatory signal - is mainly, but not only, mediated by the interaction between the CD80/CD86 molecules on the membrane of APCs with the CD28 receptor expressed by T-cells. To counteract an excessive activation of T-cells, CTLA-4 is indeed transiently expressed following T-cell activation, competing with CD28 for binding to CD80/86 and delivering a signal that downregulates cellular functions thus inducing anergy of activated T-cells (A). Abatacept (CTLA-4-lg) binds to CD80/86, exploiting the self-regulatory role of CTLA-4 in inducing T-cell anergy (B).

Abbreviations: APC, antigen-presenting cell; MHC, major histocompatibility complex; TCR, T-cell receptor.

following T-cell activation, competing with CD28 for binding to CD80/86 and delivering a signal that downregulates cellular functions, thus inducing anergy of activated T-cells. ${ }^{25}$ This finely tuned mechanism clearly represented an attractive therapeutic target in T-cell-mediated diseases.

\section{T-cells in PsA}

Although the complete cascade of events leading to the development of PsA is still elusive, extensive preclinical and clinical data support the hypothesis that PsA is a T-cell-driven inflammatory disease with a predominant immunopathological role of autoreactive $\mathrm{CD} 8^{+} \mathrm{T}$-cells. ${ }^{26}$ First, differently from many other immune-mediated diseases in which genetic susceptibility relies on specific HLA-DR or other class II MHC genes, class I genes - notably alleles belonging to the HLA-B and HLA-C loci-are preferentially involved in PsA. ${ }^{27}$ The function of class I molecules is to present small peptides to TCR expressed by CD8 ${ }^{+} \mathrm{T}$-cells. Moreover, activated $\mathrm{CD} 8^{+} \mathrm{T}$-cell clones are expanded in synovial fluid $^{28,29}$ and synovial tissue ${ }^{30}$ from PsA patients. In contrast, the $\mathrm{CD}^{+}$population - as a whole - seems to play a less relevant role in this context, given the evidence that Pso and PsA develop frequently in AIDS patients despite profound CD4+ T-cell lymphopenia. ${ }^{31}$ More recently, the traditional dichotomy between Th1- and Th2-mediated diseases has been overtaken by the identification of novel T-cell subsets, namely regulatory T-cells (Treg) and T helper 17 (Th17) populations. Tregs are characterized by the expression of the transcription factor Foxp3 and act as negative regulators of immune-mediated inflammation, ${ }^{32}$ while Th17 cells 
are IL-23-dependent cells characterized by the production of the proinflammatory cytokine IL-17 and participate in the pathophysiology of inflammatory diseases. ${ }^{33}$ Globally, their balance represents the delicate razor-blade on which T-cell-mediated inflammation develops and maintains chronically. ${ }^{34}$ In PsA synovial fluid, an enrichment of both $\mathrm{CD}^{+}$and $\mathrm{CD}^{+} \mathrm{IL}-17^{+}$cells has been described; on the contrary in RA only $\mathrm{CD}^{+}$cells produce significant amount of IL-17. ${ }^{35}$ Moreover, in PsA, IL-17 acts locally to enhance the production of inflammatory cytokines by synoviocites. ${ }^{36}$ The critical role of T-cells in Pso and PsA is further emphasized by the evidence that biologics directed against T-cell cytokines such as TNF (infliximab, adalimumab, golimumab, certolizumab, and etanercept), IL-12/23 (ustekinumab), and IL-17 (secukinumab) and surface costimulatory molecules (abatacept, efalizumab) demonstrated significant efficacy in treating both Pso and PsA. ${ }^{37,38}$

\section{Abatacept: pharmacodynamics and pharmacokinetics}

Abatacept is a fully human glycosylated soluble fusion protein (molecular weight $\sim 92 \mathrm{kDa}$ ) produced by recombinant DNA technology in mammalian CHO cells, which links the extracellular domain of human CTLA-4 to the modified Fc portion (hinge, $\mathrm{CH} 2$, and $\mathrm{CH} 3$ domains) of human immunoglobulin G1 (IgG1). ${ }^{39}$ By competitively binding to CD80/86, abatacept exploits the self-regulatory role of CTLA-4 in inducing T-cell anergy (Figure 1B).

Abatacept has been originally approved for intravenous (IV) administration, but in 2011 it received the first approval by FDA for subcutaneous (SC) delivery following the demonstration of therapeutic equivalence of the two regimens. ${ }^{40}$ Currently, the recommended IV dosage is $500 \mathrm{mg}$ for individuals weighing $<60 \mathrm{~kg}, 750 \mathrm{mg}$ for individuals $\geq 60$ to $\leq 100 \mathrm{~kg}$, and $1,000 \mathrm{mg}$ for those $>100 \mathrm{~kg}$, corresponding approximately to $10 \mathrm{mg} / \mathrm{kg}$ and administered as a 30-minutes infusion at time 0,14 , and 28 days and then every 28 days. ${ }^{39}$ For the SC delivery route, the approved dosage is $125 \mathrm{mg}$ weekly independent of body weight. ${ }^{39}$ The bioavailability of abatacept following SC administration is $78.6 \%{ }^{39}$ After IV administration, the mean terminal half-life is 13.1 days, while following SC administration is 14.3 days; however, pharmacokinetic analyses indicated that the clearance of abatacept tends to increase with body weight. ${ }^{39}$ Both $\mathrm{IV}^{41}$ and $\mathrm{SC}^{42}$ abatacept have been shown to elicit low rates of immunogenicity $(-3.0 \%$ and $\sim 3.9 \%$, respectively) that, however, was not associated with reduced efficacy or safety.

\section{Efficacy and safety of abatacept in RA}

Several clinical trials demonstrated the efficacy of IV and SC abatacept in different populations of RA patients, including MTX naïve, ${ }^{43,44}$ MTX-inadequate responders, ${ }^{40,45}$ and in those refractory to TNF inhibitors ${ }^{46,47}$ with the benefits of treatment extending beyond the mere control of disease activity to the reduction of radiographic progression. ${ }^{48}$ The safety profile has been evaluated in the long term ${ }^{49}$ without raising major concerns, and in particular with no significant increase in the risk of serious infections ${ }^{50}$ or malignancy. ${ }^{51}$ Furthermore, compared to other biologics, abatacept has been suggested to display a better safety profile in special populations, such as patients with chronic heart failure ${ }^{52}$ and demyelinating disorders. ${ }^{53}$ Finally, the benefits of abatacept may affect other disease-related domains such as the risk of cardiovascular events $^{52,54}$ by its ability to improve several well-known cardiovascular risk factors such as insulin resistance and vascular dysfunction. ${ }^{55,56}$

\section{Abatacept in PsA: current evidence Efficacy of abatacept in PsA}

Following abatacept commercialization, isolated case reports were published suggesting its potential efficacy in difficult-to-treat PsA patients. ${ }^{57-60}$ The efficacy and safety of abatacept in PsA patients was subsequently systematically evaluated in two randomized controlled trials (RCTs) ${ }^{61,62}$ ultimately leading to its approval for combination therapy in patients with PsA and inadequate response to at least one DMARD by FDA and EMA, in summer 2017.

In the first phase II, dose-ranging study by Mease et al, ${ }^{61}$ 170 patients with active PsA and inadequate response to DMARDs (including TNF inhibitors) were randomized 1:1:1:1 to receive IV abatacept at 3 different dosing regimens ( $3 \mathrm{mg} / \mathrm{kg}$ or $10 \mathrm{mg} / \mathrm{kg}$ - administered on days 1,15 , and 29 and then every 28 days - or $30 \mathrm{mg} / \mathrm{kg}$ administered on days 1 and 15 , followed by $10 \mathrm{mg} / \mathrm{kg}$ every 28 days) or placebo for 6 months. The primary endpoint (American College of Rheumatology 20\% improvement criteria-ACR20 - response on day 169 ) was achieved by $33 \%, 48 \%$, and $42 \%$ of patients respectively compared to $19 \%$ of those taking placebo and resulting in a statistically significant difference for the $10 \mathrm{mg} / \mathrm{kg}(p=0.006)$ and 30/10 mg/kg ( $p=0.022)$ groups. Of note, at the $10 \mathrm{mg} / \mathrm{kg}$ dose (the one already approved for RA), the proportion of individuals achieving an ACR20 response was higher in patients who had never received TNF inhibitors compared to those who had previously received anti-TNF agents (56\% vs 31\%). Although the study was not adequately powered to draw firm conclusions on secondary 
outcome measures, a higher number of abatacept-treated patients achieved numerically superior results on additional measures of arthritis severity (ACR50 and ACR70 response), Pso severity (target lesion 50\% - TL50 - and psoriasis area severity index 50\% response), physical function (proportion of patients achieving a minimal clinically important differences in Health Assessment Questionnaire Disability Index score), and quality of life (change in Short Form health survey score from baseline), with the $10 \mathrm{mg} / \mathrm{kg}$ regimen showing the overall best performance.

Following these results, a phase III RCT was conducted to confirm the efficacy and safety of abatacept in patients with active $\mathrm{PsA},{ }^{62}$ using the SC delivery route that has already shown therapeutic equivalence to IV one in RA patients. ${ }^{40}$ For this purpose, 424 PsA patients with inadequate response to DMARDs (including TNF inhibitors) were randomized to receive SC abatacept $125 \mathrm{mg}$ or placebo weekly for 24 weeks. The RCT phase was followed by an additional open-label treatment period of 28 weeks (resulting in a 52-weeks follow-up period) while patients who did not achieve $\geq 20 \%$ improvement in tender/swollen joints count at week 16 were switched to open-label abatacept for 28 weeks (early escape strategy, total follow-up 44 weeks).

Abatacept treatment resulted in a significantly higher proportion of patients achieving the primary endpoint (ACR20 response) at week $24(39.4 \%$ vs $22.3 \%$; $p<0.001)$ with the largest treatment difference seen in anti-TNF naïve patients and in those with $\mathrm{C}$-reactive protein above the upper limit of normal at baseline. Intention-to-treat analysis at week 44 showed that ACR20 response was maintained in patients treated with abatacept and improved in those who switched from placebo. Efficacy on musculoskeletal manifestations was further supported by greater improvement in disease activity score including 28 joints and disease activity in PsA scores, a higher percentage of patients achieving ACR50 and ACR70 responses, percentage of patients achieving complete resolution of enthesitis and dactylitis, and proportion of patient without radiographic progression. Finally, the proportion of patients achieving Health Assessment Questionnaire Disability Index endpoint was numerically superior (although not reaching statistical significance) while measures of skin response were only slightly numerically improved in the abatacept arm.

It is noteworthy that the ACR20 response rate at week 24 in both studies was globally lower than that observed in previous studies of agents targeting other effector molecules in PsA. However, both studies included a significant proportion of anti-TNF exposed patients (30\% and 60\%, respectively) which may indicate a more treatment-refractory population. Furthermore, differently from what observed with other agents exploiting diverse mechanisms of action, abatacept demonstrated a stronger efficacy on musculoskeletal compared to skin endpoints. The reasons for this discrepancy may underlie an incomplete understanding of the divergent role of individual $\mathrm{T}$-cell subsets and costimulatory pathways in orchestrating skin and synovial inflammation in psoriatic disease. Indeed, opposite to abatacept, the tight inhibition of the costimulatory signal delivered through the CD2/LFA-3 pathway by means of the fusion protein alefacept resulted in a significant improvement of skin lesions but was burdened by a decline of $\mathrm{CD}^{+} \mathrm{T}$-cells and subsequent increase of infectious adverse events (AEs); ${ }^{63}$ for this reason, the drug was voluntarily discontinued by the manufacturer in 2011 . In contrast, selective targeting of the IL-23/IL-17 axis produces superior results on skin lesions without a similar level of efficacy in the joints. ${ }^{64}$ Finally, another potential reason explaining the divergence between skin and joint endpoints may be related to the interference of abatacept with the protective function of Tregs, thus accounting for the relative superior efficacy of lower doses in treatment of cutaneous manifestations. ${ }^{65,66}$

\section{Safety of abatacept in PsA}

In both studies, abatacept was generally well tolerated with no emerging safety signals with respect to what observed in RA patients. ${ }^{67}$

In the phase II study, ${ }^{61}$ AEs were reported in $\sim 70 \%$ of patients in each treatment arm. Seven patients developed serious adverse events (SAEs), of whom 4 were in the $30 / 10 \mathrm{mg} / \mathrm{kg}$ arm, 2 in the $10 \mathrm{mg} / \mathrm{kg}$ arm, and 1 in the placebo arm; only $1 \mathrm{SAE}$ in the $30 / 10 \mathrm{mg} / \mathrm{kg}$ (osteomyelitis) and in the $10 \mathrm{mg} / \mathrm{kg}$ (gastroenteritis) arms, respectively, were attributed as drug-related. Infusion reactions were reported in 4 patients ( 2 in the $30 / 10 \mathrm{mg} / \mathrm{kg}$ arm and 2 in the $10 \mathrm{mg} / \mathrm{kg}$ arm).

Similarly, in the 24-week double-blind period of the phase III trial, ${ }^{62}$ the safety profile of abatacept was analogous of that observed in the placebo group, with comparable incidences of AEs (54.5\% vs 53.1\%) and SAEs (2.8\% vs $4.3 \%$ ). Only 1 serious infection (Pneumocystis jirovecii infection) was considered related to study drug and led to treatment discontinuation. A similar favorable safety profile was consistently maintained throughout the open-label phase, up to week 52 . 


\section{Conclusion}

Recent data from clinical trials demonstrated that abatacept represents a novel weapon in fighting the battle against PsA. However, many issues need still to be clarified in future studies: the potential benefits of a dosage adjustment in PsA patients with extensive skin involvement; the long-term efficacy and safety in real-life setting, the differential efficacy in different disease domains (enthesitis, dactylitis, cardiometabolic risk) and patients categories (csDMARDs naïve, bDMARDs naïve) and, finally, the comparative efficacy in direct comparison with other available molecules and the correct positioning in current treatment algorithms.

\section{Acknowledgment}

In loving memory of our Master and friend Prof Ignazio Olivieri.

\section{Disclosure}

The authors report no conflicts of interest in this work.

\section{References}

1. Ritchlin CT, Colbert RA, Gladman DD. Psoriatic arthritis. $N$ Engl $J$ Med. 2017;376(10):957-970.

2. Ursini F, D'Angelo S, Russo E, et al. Complement C3 is the strongest predictor of whole-body insulin sensitivity in psoriatic arthritis. PLoS One. 2016;11(9):e0163464.

3. Ursini F, Grembiale A, Naty S, Grembiale RD. Serum complement C3 correlates with insulin resistance in never treated psoriatic arthritis patients. Clin Rheumatol. 2014;33(12):1759-1764.

4. Gelfand JM, Yeung H. Metabolic syndrome in patients with psoriatic disease. J Rheumatol Suppl. 2012;89:24-28.

5. Schieir O, Tosevski C, Glazier RH, Hogg-Johnson S, Badley EM. Incident myocardial infarction associated with major types of arthritis in the general population: a systematic review and meta-analysis. Ann Rheum Dis. 2017;76(8):1396-1404.

6. Ritchlin C. Psoriatic disease - from skin to bone. Nat Clin Pract Rheumatol. 2007;3(12):698-706.

7. Lemos LL, de Oliveira Costa J, Almeida AM, et al. Treatment of psoriatic arthritis with anti-TNF agents: a systematic review and metaanalysis of efficacy, effectiveness and safety. Rheumatol Int. 2014; 34(10):1345-1360.

8. Giacomelli R, Afeltra A, Alunno A, et al. International consensus: what else can we do to improve diagnosis and therapeutic strategies in patients affected by autoimmune rheumatic diseases (rheumatoid arthritis, spondyloarthritides, systemic sclerosis, systemic lupus erythematosus, antiphospholipid syndrome and Sjogren's syndrome)?: the unmet needs and the clinical grey zone in autoimmune disease management. Autoimmun Rev. 2017;16(9):911-924.

9. Skapenko A, Leipe J, Lipsky PE, Schulze-Koops H. The role of the $\mathrm{T}$ cell in autoimmune inflammation. Arthritis Res Ther. 2005; 7(Suppl 2):S4-S14.

10. Orban T, Bundy B, Becker DJ, et al. Costimulation modulation with abatacept in patients with recent-onset type 1 diabetes: follow-up 1 year after cessation of treatment. Diabetes Care. 2014;37(4):1069-1075.

11. Langford CA, Cuthbertson D, Ytterberg SR, et al. A randomized, double-blind trial of abatacept (CTLA-4Ig) for the treatment of giant cell arteritis. Arthritis Rheumatol. 2017;69(4):837-845.
12. Tjarnlund A, Tang Q, Wick C, et al. Abatacept in the treatment of adult dermatomyositis and polymyositis: a randomised, phase IIb treatment delayed-start trial. Ann Rheum Dis. 2018;77(1):55-62.

13. Meiners PM, Vissink A, Kroese FG, et al. Abatacept treatment reduces disease activity in early primary Sjogren's syndrome (open-label proof of concept ASAP study). Ann Rheum Dis. 2014;73(7):1393-1396.

14. Merrill JT, Burgos-Vargas R, Westhovens R, et al. The efficacy and safety of abatacept in patients with non-life-threatening manifestations of systemic lupus erythematosus: results of a twelve-month, multicenter, exploratory, phase IIb, randomized, double-blind, placebo-controlled trial. Arthritis Rheum. 2010;62(10):3077-3087.

15. Langford CA, Cuthbertson D, Ytterberg SR, et al. A randomized, doubleblind trial of abatacept (CTLA-4Ig) for the treatment of Takayasu arteritis. Arthritis Rheumatol. 2017;69(4):846-853.

16. Sandborn WJ, Colombel JF, Sands BE, et al. Abatacept for Crohn's disease and ulcerative colitis. Gastroenterology. 2012;143(1):62-69.e4.

17. Khoury SJ, Rochon J, Ding L, et al. ACCLAIM: a randomized trial of abatacept (CTLA4-Ig) for relapsing-remitting multiple sclerosis. Mult Scler. 2017;23(5):686-695.

18. Coates LC, Kavanaugh A, Mease PJ, et al. Group for research and assessment of psoriasis and psoriatic arthritis 2015 treatment recommendations for psoriatic arthritis. Arthritis Rheumatol. 2016;68(5): $1060-1071$.

19. Gossec L, Smolen JS, Ramiro S, et al. European League Against Rheumatism (EULAR) recommendations for the management of psoriatic arthritis with pharmacological therapies: 2015 update. Ann Rheum Dis. 2016;75(3):499-510.

20. Chen L, Flies DB. Molecular mechanisms of T cell co-stimulation and co-inhibition. Nat Rev Immunol. 2013;13(4):227-242.

21. Yamada A, Salama AD, Sayegh MH. The role of novel T cell costimulatory pathways in autoimmunity and transplantation. J Am Soc Nephrol. 2002;13(2):559-575.

22. Green JM, Karpitskiy V, Kimzey SL, Shaw AS. Coordinate regulation of T cell activation by CD2 and CD28. J Immunol. 2000;164(7): 3591-3595.

23. Lenschow DJ, Walunas TL, Bluestone JA. CD28/B7 system of T cell costimulation. Annu Rev Immunol. 1996;14:233-258.

24. Berard M, Tough DF. Qualitative differences between naive and memory T cells. Immunology. 2002;106(2):127-138.

25. Perkins D, Wang Z, Donovan C, et al. Regulation of CTLA-4 expression during T cell activation. J Immunol. 1996;156(11):4154-4159.

26. Cai Y, Fleming C, Yan J. New insights of T cells in the pathogenesis of psoriasis. Cell Mol Immunol. 2012;9(4):302-309.

27. Hebert HL, Ali FR, Bowes J, Griffiths CE, Barton A, Warren RB. Genetic susceptibility to psoriasis and psoriatic arthritis: implications for therapy. Br J Dermatol. 2012;166(3):474-482.

28. Costello PJ, Winchester RJ, Curran SA, et al. Psoriatic arthritis joint fluids are characterized by CD8 and CD4 T cell clonal expansions appear antigen driven. J Immunol. 2001;166(4):2878-2886.

29. Costello P, Bresnihan B, O'Farrelly C, FitzGerald O. Predominance of CD8+ T lymphocytes in psoriatic arthritis. J Rheumatol. 1999;26(5): $1117-1124$

30. Curran SA, FitzGerald OM, Costello PJ, et al. Nucleotide sequencing of psoriatic arthritis tissue before and during methotrexate administration reveals a complex inflammatory $\mathrm{T}$ cell infiltrate with very few clones exhibiting features that suggest they drive the inflammatory process by recognizing autoantigens. J Immunol. 2004;172(3):1935-1944.

31. Arnett FC, Reveille JD, Duvic M. Psoriasis and psoriatic arthritis associated with human immunodeficiency virus infection. Rheum Dis Clin North Am. 1991;17(1):59-78.

32. Josefowicz SZ, Lu LF, Rudensky AY. Regulatory T cells: mechanisms of differentiation and function. Annu Rev Immunol. 2012;30:531-564.

33. Bettelli E, Korn T, Oukka M, Kuchroo VK. Induction and effector functions of T(H)17 cells. Nature. 2008;453(7198):1051-1057.

34. Noack M, Miossec P. Th17 and regulatory T cell balance in autoimmune and inflammatory diseases. Autoimmun Rev. 2014;13(6):668-677. 
35. Menon B, Gullick NJ, Walter GJ, et al. Interleukin-17+CD8+ T cells with disease activity and joint damage progression. Arthritis Rheumatol. 2014;66(5):1272-1281.

36. Raychaudhuri SP, Raychaudhuri SK, Genovese MC. IL-17 receptor and its functional significance in psoriatic arthritis. Mol Cell Biochem. 2012;359(1-2):419-429.

37. D’Angelo S, Tramontano G, Gilio M, Leccese P, Olivieri I. Review of the treatment of psoriatic arthritis with biological agents: choice of drug for initial therapy and switch therapy for non-responders. Open Access Rheumatol. 2017;9:21-28.

38. D’Angelo S, Carriero A, Gilio M, Ursini F, Leccese P, Palazzi C. Safety of treatment options for spondyloarthritis: a narrative review. Expert Opin Drug Saf. Epub 2018 Mar 5.

39. European Medicines Agency (EMA). Abatacept (Orencia) European public assessment report (EPAR) product information. Updated August 9, 2017.

40. Genovese MC, Covarrubias A, Leon G, et al. Subcutaneous abatacept versus intravenous abatacept: a phase IIIb noninferiority study in 2011;63(10):2854-2864.

41. Haggerty HG, Abbott MA, Reilly TP, et al. Evaluation of immunogenicity of the T cell costimulation modulator abatacept in patients treated for rheumatoid arthritis. J Rheumatol. 2007;34(12):2365-2373.

42. Nash P, Nayiager S, Genovese MC, et al. Immunogenicity, safety, and efficacy of abatacept administered subcutaneously with or without background methotrexate in patients with rheumatoid arthritis: results from a phase III, international, multicenter, parallel-arm, open-label study. Arthritis Care Res. 2013;65(5):718-728.

43. Westhovens R, Robles M, Ximenes AC, et al. Clinical efficacy and safety of abatacept in methotrexate-naive patients with early rheumatoid arthritis and poor prognostic factors. Ann Rheum Dis. 2009;68(12):1870-1877.

44. Emery P, Burmester GR, Bykerk VP, et al. Evaluating drug-free remission with abatacept in early rheumatoid arthritis: results from the phase $3 \mathrm{~b}$, multicentre, randomised, active-controlled AVERT study of 24 months, with a 12-month, double-blind treatment period. Ann Rheum Dis. 2015; 74(1):19-26

45. Kremer JM, Genant HK, Moreland LW, et al. Effects of abatacept a randomized trial. Ann Intern Med. 2006;144(12):865-876.

46. Genovese MC, Becker JC, Schiff M, et al. Abatacept for rheumatoid arthritis refractory to tumor necrosis factor alpha inhibition. $N$ Engl J Med. 2005;353(11):1114-1123.

47. Schiff M, Pritchard C, Huffstutter JE, et al. The 6-month safety and efficacy of abatacept in patients with rheumatoid arthritis who underwent a washout after anti-tumour necrosis factor therapy or were directly switched to abatacept: the ARRIVE trial. Ann Rheum Dis. 2009;68(11): 1708-1714.

48. Kremer JM, Russell AS, Emery P, et al. Long-term safety, efficacy and inhibition of radiographic progression with abatacept treatment in patients with rheumatoid arthritis and an inadequate response to methotrexate: 3-year results from the AIM trial. Ann Rheum Dis. 2011;70(10): 1826-1830.

49. Weinblatt ME, Moreland LW, Westhovens R, et al. Safety of abatacept administered intravenously in treatment of rheumatoid arthritis: integrated analyses of up to 8 years of treatment from the abatacept clinical trial program. J Rheumatol. 2013;40(6):787-797. are enriched in the joints of patients with psoriatic arthritis and correlate patients with an inadequate response to methotrexate. Arthritis Rheum. in patients with methotrexate-resistant active rheumatoid arthritis:

50. Salliot C, Dougados M, Gossec L. Risk of serious infections during rituximab, abatacept and anakinra treatments for rheumatoid arthritis: meta-analyses of randomised placebo-controlled trials. Ann Rheum Dis. 2009;68(1):25-32.

51. Simon TA, Smitten AL, Franklin J, et al. Malignancies in the rheumatoid arthritis abatacept clinical development programme: an epidemiological assessment. Ann Rheum Dis. 2009;68(12):1819-1826.

52. Kang EH, Jin Y, Brill G, et al. Comparative cardiovascular risk of abatacept and tumor necrosis factor inhibitors in patients with rheumatoid arthritis with and without diabetes mellitus: a multidatabase cohort study. J Am Heart Assoc. 2018;7(3):e007393.

53. D'Angelo STG, Gilio M, Abignano G, et al. Abatacept in patients with inflammatory chronic arthritis and demyelinating disorders: case series and systematic literature review. Submitted article. 2018.

54. Ursini F, Leporini C, Bene F, et al. Anti-TNF-alpha agents and endothelial function in rheumatoid arthritis: a systematic review and metaanalysis. Sci Rep. 2017;7(1):5346.

55. Ursini F, Russo E, Letizia Hribal M, et al. Abatacept improves wholebody insulin sensitivity in rheumatoid arthritis: an observational study. Medicine. 2015;94(21):e888.

56. Ursini F, Russo E, Ruscitti P, Giacomelli R, De Sarro G. The effect of non-TNF-targeted biologics and small molecules on insulin resistance in inflammatory arthritis. Autoimmun Rev. 2018;17(4):399-404.

57. Ursini F, Naty S, Russo E, Grembiale RD. Abatacept in psoriatic arthritis: case report and short review. J Pharmacol Pharmacother. 2013 ; 4(Suppl 1):S29-S32.

58. Altmeyer MD, Kerisit KG, Boh EE. Therapeutic hotline. Abatacept: our experience of use in two patients with refractory psoriasis and psoriatic arthritis. Dermatol Ther. 2011;24(2):287-290.

59. Rodrigues CE, Vieira FJ, Callado MR, Gomes KW, de Andrade JE, Vieira WP. Use of the abatacept in a patient with psoriatic arthritis. Rev Bras Reumatol. 2010;50(3):340-345.

60. Vieira FJ, Callado MR, Vieira WP. Abatacept as an option therapy in difficult to treat psoriatic arthritis. Rheumatol Int. 2010;30(6):849-850.

61. Mease P, Genovese MC, Gladstein G, et al. Abatacept in the treatment of patients with psoriatic arthritis: results of a six-month, multicenter, randomized, double-blind, placebo-controlled, phase II trial. Arthritis Rheum. 2011;63(4):939-948.

62. Mease PJ, Gottlieb AB, van der Heijde D, et al. Efficacy and safety of abatacept, a T-cell modulator, in a randomised, double-blind, placebocontrolled, phase III study in psoriatic arthritis. Ann Rheum Dis. 2017; 76(9):1550-1558.

63. Scheinfeld N. Alefacept: a safety profile. Expert Opin Drug Saf. 2005;4(6):975-985.

64. Meng Y, Dongmei L, Yanbin P, et al. Systematic review and metaanalysis of ustekinumab for moderate to severe psoriasis. Clin Exp Dermatol. 2014;39(6):696-707.

65. Szentpetery A, Heffernan E, Gogarty M, et al. Abatacept reduces synovial regulatory $\mathrm{T}$-cell expression in patients with psoriatic arthritis Arthritis Res Ther. 2017;19(1):158.

66. Iannone F, Lapadula G. The inhibitor of costimulation of T cells: abatacept. J Rheumatol Suppl. 2012;89:100-102.

67. Schiff M. Subcutaneous abatacept for the treatment of rheumatoid arthritis. Rheumatology. 2013;52(6):986-997.

\section{Dovepress}

\section{Publish your work in this journal}

Therapeutics and Clinical Risk Management is an international, peerreviewed journal of clinical therapeutics and risk management, focusing on concise rapid reporting of clinical studies in all therapeutic areas, outcomes, safety, and programs for the effective, safe, and sustained use of medicines. This journal is indexed on PubMed Central, CAS,
EMBase, Scopus and the Elsevier Bibliographic databases. The manuscript management system is completely online and includes a very quick and fair peer-review system, which is all easy to use. Visit http://www.dovepress.com/testimonials.php to read real quotes from published authors. 